\title{
Long-term implications and global impact of paediatric surgery
}

Irrespective of variations across geography, culture, and socioeconomic status, paediatric surgery differs from other surgical subspecialties. Children are not small adults. Surgery for infants and children is typically undertaken for congenital, rare, and complex conditions and the consequences of both the condition and its treatment can affect that individual for life. Above all, the surgical outcome needs to stand the test of time. Our Lancet Series papers in this issue on advances in paediatric urology $\mathrm{y}_{1}$ and gastroenterology $\mathrm{y}_{2}$ highlight the transition of paediatric surgery from a focus on shortterm patient survival to evidence and innovations for long-term quality of life globally. We believe the lessons and challenges have wide implications and offer insights into how knowledge gaps can be filled and new treatments designed.

Most paediatric surgery requires general anaesthesia and concern about anaesthetic agents harming the developing brain has been raised by some experimental animal studies. The 2016 US Food and Drug Administration's warning about possible neurodevelopmental effects of anaesthetic and sedative drugs in infants younger than 3 years and in the fetus during the third trimester should, however, be interpreted with caution. ${ }_{3}$ Evidence of harm in human beings is inconclusive and, reassuringly, a randomised controlled trial ${ }_{4}$ has shown no mediumterm adverse neurodevelopmental effects after a single general anaesthetic during infancy. Nevertheless, the long-term outcome of repeated or lengthy anaesthetic exposure, especially in more vulnerable subgroups such as premature infants, remains unknown. This potential risk of anaesthesia in infancy has created a dilemma about whether to delay the timing of surgery until after the age 3 years for elective conditions such as hypospadias and craniofacial anomalies in which early correction can confer functional and psychocosmetic benefits.5 Surgical decisions made in infancy and childhood have even more profound effects on adult life in the management of some disorders of sexual development (DSD). In the past, decisions about genital surgery and assignation of gender were made during infancy and remained a compact between the surgical team and the parents and did not account for underlying ethical implications related to the exclusion of patient's choice. Surgeons are now more aware of the problems arising from surgery for DSD in infancy. For example, early reduction clitoroplasty for enlarged clitoris in female DSD can compromise later sexual function ${ }_{6}$ and often leads to major concerns about gender identity, body habitus, and psychosexual functioning. ${ }_{7}$ Although the exact timing of reconstructive surgery remains controversial, common practice follows the Chicago DSD Consensus guidelines. ${ }_{8}$ Ethical considerations also 
affect surgical management for other conditions such as total intestinal aganglionosis in which surgery results in a major health burden of life-long total parenteral nutrition. ${ }^{2}$ When parental wishes and surgical opinions differ, for example in end-of-life decisions for multiple anomalies, the medical community has to be prepared for ethical, legal, and public debate.

Quality of life in adults with DSD is also affected by hormonal replacement, issues with fertility, an increased risk of malignancy, and personal, family, and cultural perceptions of "normal" sex development.7 Many adults with complex anorectal malformations similarly experience sexual dysfunction and more than $50 \%$ of children with such congenital malformations need special education.10-12 In terms of increased risk of malignancy, there can be a predisposition to laterlife malignancy inherent in the condition (eg, DSD, undescended testes, or choledochal cysts), ${ }_{13}$ or the actual nature of the surgical reconstruction can predispose

to cancer (eg, gastrocystoplasty or colocystoplasty for

neurogenic bladder).14,15

Successful transition of care for patients with paediatric surgical conditions from childhood to adulthood requires policy support, ${ }_{16}$ an international consensus, ${ }_{17}$ and a well developed action plan over many years. Important elements of this long-term care are for patients to become educated about their conditions and participate actively in their own care and for systematic follow-up by a multidisciplinary team of paediatric and adult specialists and health carers.18,19

Transition of care is one challenge. We must also make use of technology and science to advance paediatric surgery to benefit more patients. The effect of highcost technology is a challenge. Although minimally invasive surgery is technically feasible for many common conditions in childhood, ${ }_{1,2}$ good quality evidence is scarce and uptake remains patchy in many parts of the world. ${ }_{20}$ Perhaps it is not only how you do an operation but also whether an experienced surgeon does it and where the operation is done that could provide lessons for improving paediatric surgery. Centralisation of resources and personnel to allow the development of multidisciplinary teams with sufficient surgical familiarity of rare conditions and accumulation of volume for randomised clinical trials seems an obvious solution. 21 The complexity of congenital anomalies often calls for innovative solutions. Paediatric surgery has been at the forefront of surgical advances, including pioneering fetal surgery ${ }_{22}$ and tissue engineering ${ }_{, 23}$ introducing an extra-uterine system for extreme prematurity,24 and developing genetic and stem-cell research such as CRISPR technology to correct underlying mutations.2

There are, of course, parts of the world where such applications are unavailable and where the provision of 
simple, safe surgery near the community is the priority. The Global Initiative on Children's Surgery ${ }_{25}$ campaigns on such needs in low-income and middle-income countries. Indeed, the high cost of minimally invasive technology can be mitigated in such settings, as has been seen in China 26 and South Africa. 27 This approach needs smart use of basic reusable equipment, and widespread implementation may be achieved through structured and innovative training, including the use of digital media.26,27 Adopting up-todate practice not only benefits more children but can also help to stem the potential brain drain of well trained surgeons from low-income and middle-income countries. Substantial challenges remain in paediatric surgery and overcoming them will require dedication, effort, and commitment. Our children deserve nothing less. *Paul K H Tam, Mark Davenport, Ivy H Y Chan, Alp Numanoglu, Piet Hoebeke, David A Diamond Department of Surgery, Li Ka Shing Faculty of Medicine, The University of Hong Kong, Queen Mary Hospital, Hong Kong (PKHT, IHYC); Department of Paediatric Surgery, King's College Hospital, London, UK (MD); Division of Paediatric Surgery, University of Cape Town, Red Cross War Memorial Children's Hospital, Cape Town, South Africa (AN); Department of Urology, Ghent University Hospital, University of Ghent, Ghent, Belgium $(\mathrm{PH})$; and Department of Urology, Boston Children's Hospital, Harvard Medical School, Boston, USA (DAD) paultam@hku.hk We declare no competing interests. 1 Diamond DA, Chan IHY, Holland AJA, et al. Advances in paediatric urology. Lancet 2017; 390: 1061-71.

2 Tam PKH, Chung PHY, St Peter SD, et al. Advances in paediatric gastroenterology. Lancet 2017; 390: 1072-82.

3 Polaner DM, Zuk J, McCann ME, Davidson A. Warnings, uncertainty, and clinical practice. Lancet 2017; 389: 2174-76.

4 Davidson AJ, Disma N, de Graaff JC, et al. Neurodevelopmental outcome at 2 years of age after general anaesthesia and awake-regional anaesthesia in infancy (GAS): an international multicentre, randomised controlled trial. Lancet 2016; 387: 239-50.

5 Davidson A, Vutskits L. The new FDA drug safety communication on the use of general anesthetics in young children: what should we make of it? Pediatr Anesth 2017; 27: 336-37.

6 Minto CL, Liao LM, Woodhouse CR, Ransley PG, Creighton SM. The effect of clitoral surgery on sexual outcome in individuals who have intersex conditions with ambiguous genitalia: a cross-sectional study. Lancet 2003; 361: 1252-57. 7 Schober J, Nordenstrom A, Hoebeke P, et al. Disorders of sex development: summaries of long-term outcome studies. J Pediatr Urol 2012; 8: 616-23. 8 Diamond DA. The ethics of gender in pediatric reconstructive urology. J Urol 2016; 196: 305-07.

9 Hazebroek FWJ, Tibboel D, Wijnen RM. Ethical aspects of care in the newborn surgical patient. Semin Pediatr Surg 2014: 23: 309-13.

9 Tourchi A, Hoebeke P. Long-term outcome of male genital reconstruction in childhood. J Pediatr Urol 2013; 9: 980-89.

10 Kyrklund K, Taskinen S, Rintala RJ, Pakarinen MP. Sexual function, fertility and quality of life after modern treatment of anorectal malformations. $\mathrm{J}$ Urol 2016; 196: 1741-46.

11 Springford LR, Connor MJ, Jones K, Kapetanakis VV, Giuliani S. Prevalence of active long-term problems in patients with anorectal malformations: a systematic review. Dis Colon Rectum 2016; 59: 570-80.

12 van den Hondel D, Aarsen FK, Wijnen RM, Sloots CE, IJsselstijn H. Children with congenital colorectal malformations often require special education or remedial teaching, despite normal intelligence. Acta Paediatr 2016; 105: e77-84.

13 Ohashi T, Wakai T, Kubota M, et al. Risk of subsequent biliary malignancy in patients undergoing cyst excision for congenital choledochal cysts. J Gastroenterol Hepatol 2013; 28: 243-47.

14 Castellan M, Gosalbez R, Perez-Brayfield M, et al. Tumor in bladder reservoir after gastrocystoplasty. J Urol 2007; 178: 1771-74.

15 Hamid R, Greenwell TJ, Nethercliffe JM, Freeman A, Venn SN, Woodhouse CR. Routine surveillance cystoscopy for patients with augmentation and substitution cystoplasty for benign urological conditions: is it necessary? BJU Int 2009; 104: 392-95. 
16 Kelleher K, Deans KJ, Chisolm DJ. Federal policy supporting improvements in transitioning from pediatric to adult surgery services. Semin Pediatr Surg 2015; 24: 61-64.

17 Giuliani S, Decker E, Leva E, Riccipetitoni G, Bagolan P. Long term follow-up and transition of care in anorectal malformations: an international survey.

J Pediatr Surg 2016; 51: 1450-57.

16 Kelleher K, Deans KJ, Chisolm DJ. Federal policy supporting improvements in transitioning from pediatric to adult surgery services. Semin Pediatr Surg

2015; 24: 61-64.

17 Giuliani S, Decker E, Leva E, Riccipetitoni G, Bagolan P. Long term follow-up and transition of care in anorectal malformations: an international survey.

J Pediatr Surg 2016; 51: 1450-57.

18 McCracken KA, Fallat ME. Transition from pediatric to adult surgery care for patients with disorders of sexual development. Semin Pediatr Surg 2015;

24: 88-92.

19 Wood D. Leading contributors to success of transitional urology units. Curr Opin Urol 2017; 27: 7-10.

20 Davenport M, Rothenberg SS, Crabbe DC, Wulkan ML. The great debate: open or thoracoscopic repair for oesophageal atresia or diaphragmatic

hernia. J Pediatr Surg 2015; 50: 240-46.

21 Davenport M, De Ville de Goyet J, Stringer MD, et al. Seamless management of biliary atresia in England and Wales (1999-2002). Lancet 2004;

363: 1354-57.

22 Kabagambe SK, Chen YJ, Farmer DL. Fetal surgery for myelomeningocele: current clinical practice and translational research. Minerva Pediatr 2017;

69: 59-65.

23 Langer R, Vacanti J. Advances in tissue engineering. J Pediatr Surg 2016;

51: 8-12.

24 Partridge EA, Davey MG, Hornick MA, et al. An extra-uterine system to

physiologically support the extreme premature lamb. Nat Commun 2017;

8: 15112.

25 Ozgediz D, Langer M, Kisa P, Poenaru D. Pediatric surgery as an essential component of global child health. Semin Pediatr Surg 2016; 25: 3-9.

26 Tam PKH, Wong KKY, Li L, Zhang JZ. Internationalization: the Hong Kong-

China experience as a model for collaborative education in Asia.

Pediatr Surg Int 2013; 29: 1053-59.

27 Loveland J, Numanoglu A, Hay SA. Pediatric minimally invasive surgery in Africa: limitations and current situation. Semin Pediatr Surg 2012;

21: $160-63$. 